\title{
As múltiplas interfaces do duplo em Tlön, Uqbar, Orbius Tertius: metafísica da ficção e ficção da metafísica em um conto de Borges
}

\author{
IRLIM CORRÊA LIMA JÚNIOR *
}

* PUC-Rio

Doutorando em Filosofia

Bolsista CAPES
RESUMO Amplamente estudado em teoria literária, psicologia, antropologia etc., o duplo é um tema universalmente recorrente na literatura, mas muito especialmente a partir do século XIX, quando se transformou em um recurso amiúde explorado e consagrado por uma gama imensa de autores, mostrando-se um terreno fértil para se refletir acerca de zonas limítrofes que demarcam a interseção e a reversibilidade entre fenômenos complementares como identidade e alteridade, normalidade e loucura, realidade e ficção, entre outros. Aproveitando-nos de pontos nodais que são elementos clássicos na composição ficcional do duplo, como as figuras do espelho e da sombra, ou do acossamento e da paranoia, investigaremos a aparição do duplo no conto Tlön, Uqbar, Orbius Tertius, ficção do escritor argentino Jorge Luís Borges. Estes três nomes que dão título ao conto são formas múltiplas de manifestação do duplo, que, nesta narrativa borgeana, não assinala a duplicação de um personagem, mas sim do mundo, espelhando-o de forma eximiamente complexa, com funcionamento inteiramente peculiar e de natureza supostamente ficcional, o qual, como uma sombra ou um espectro, acossaria a realidade, a princípio misteriosamente insistindo por ser descoberta, até que o fascínio e a curiosidade do narrador-personagem por esse duplo que espelha o mundo, com características antagônicas, resulta numa fresta a partir da qual duplo do mundo transforma-se na ameaça à realidade de ser revertida inteiramente numa obra de ficção. Nosso objetivo, então, será destrinchar os elementos cruciais que constituem a estrutura do duplo neste conto de Borges, não como uma ocorrência atípica ou regular no processo de individuação de uma subjetividade, mas sim como duplicação procedural e metafísica a partir da qual a realidade da ficção e a ficcionalidade do real mutuamente se instanciam, se recusam e se ameaçam.

PALAVRAS-ChaVe Borges; Duplo; Ficção; Realidade; Metafísica. 
"As mil e uma noites não morreram... continuam crescendo, ou recriando-se. E o infinito tempo do livro continua seu caminho."

Jorge Luis Borges, Sete noites

SовR a superfície de um espelho desliza-se um real que se desrealiza em imagem a fim de realizar a si mesmo como um outro corpo, a partir do qual ambos se graduam em dupla virtualidade. A tensão entre esse duplo hemisfério de realidade e de desrealização possui como condição um invisível hiato, por onde se costura uma distorção dissimulada em simulação, em cujo raio de ação um jardim de veredas e de possibilidades se bifurcam sem, contudo, deixarem de se entroncar. Um espelho, com efeito, é um evento quântico que colapsa num só ato, num único mas prolífero átimo, uma dupla flexão imagética: simulacro e distorção concentrados numa imagem inquietantemente familiar e diferencialmente estranha. Assim, o real fragmenta-se e multiplica-se em sua absoluta impotência de unicidade e, portanto, de univocidade. No espelho, revela-se o negativo de sua essência em duplicata: que o real só pode subsistir e ser originado enquanto sofrer inexpugnavelmente uma espécie de metástase. É na interseção entre realidade e ficção que penetra a escrita de Jorge Luis Borges, justamente inoculando nessa ferida aberta o poder da literatura de narrar e criar mundos. Ferida que é ponto de ebulição de uma junção vital entre duas esferas disjuntivas. E só assim podemos efetivamente conhecer por que razão se faz mister encetar a narrativa de seu conto que abre suas Fiç̧ões precisamente com a conjunção entre um espelho e uma enciclopédia, e por que então o mundo torna-se um plano monstruoso de disjunção. Mundo que passa, portanto, a compaginar-se à infinidade de páginas escritas, não-escritas, desescritas e a serem escritas onde constariam, nem que fosse de forma críptica, qual numa biblioteca que se multiplica aos espelhos infinitamente, suas múltiplas versões verossímeis e impossíveis.

A figura da enciclopédia porta uma carga simbólica, e da mesma forma o espelho, ambos diferencialmente preenchendo-se em suas projeções e faltas. A enciclopédia é um compêndio do mundo, o resultado de uma produção textual hecatônquira, de 
tecer com infinitas vozes e mãos, de uma série de autores e de esforços intelectuais de se coligir sumariamente o saber acumulado pela humanidade e mapear com esse conhecimento o mundo conhecido. Na enciclopédia os autores são obliterados pelo projeto intelectual e literário que os arregimentou anteriormente e que os perpassa e transcende. São puro anonimato diante desse gigantesco e fragmentado corpo textual - todos os nomes são esquecidos, subsumidos e abduzidos para dentro de um único nome, o da enciclopédia, nome que por sua vez pretende creditar a síntese de um espelhamento do mundo a um engenho entretecido e entrecortado de múltiplas personalidades, mas cujo resultado final é a obra magna de um desígnio impessoal e anônimo. Borges, contudo, magistralmente não toma um original de uma enciclopédia como a origem de desoriginação da realidade que vai orquestrar ou narrar em seu conto, mas justamente numa versão de reimpressão, sob outro nome, que desfigura num outro anonimato o anonimato de um espelhamento pseudoriginário. Assim, a própria enciclopédia de onde o nome de Uqbar é extraído é ela própria, enquanto uma reimpressão tardia e que, de acordo com o narrador, "falazmente se chama The Anglo-American Cyclopaedia" , um espelhamento, no caso de uma edição anterior, a Encyclopaedia Britannica. Da conjunção, portanto, entre um espelho e uma enciclopédia que não passa de um espelho de uma outra, um nome estranho ocorre à narrativa e a seus personagens, nome que não remete a nada de conhecido, nome na verdade que salta à recordação de um personagem como referência aos heresiarcas desse lugar, os quais consideravam os espelhos e as cópulas abomináveis.

A abominação ao espelho revela-se a contraparte de seu fascínio. O espelho, aos olhos do narrador, espreita, inquieta. Nesse olhar cego que o espelho é capaz de lançar contém-se algo de monstruoso, como se a imagem ali lançada de alguma forma ganhasse vida, ou como se o poder da imagem fosse tamanho a ponto de transformar o que se julga original apenas uma imagem. O espelho é fonte de um fascínio narcisista, mas também de inquietação paranoica. Na novela de Dostoievski intitulada O duplo, a narrativa abre com o culto da imagem do protagonista diante do espelho, autoimagem que, por uma série de acontecimentos vexatórios e por instinto de culpa e de autopunição do mesmo, vai ser estraçalhada até, contudo, ganhar forma em outro corpo idêntico ao do protagonista, seu sósia, seu duplo, o qual, no entanto, se transforma

1 BORGES, Tlön, Uqbar, Orbius Tertius, p. 114. 
em seu rival, uma versão muito mais bem sucedida socialmente do que o protagonista e que, por esta razão, ameaça-o de substituir sua vida fracassada.

Amplamente estudado em teoria literária, psicanálise, antropologia etc., o duplo é um tema universalmente recorrente na literatura de todos os tempos, mas muito especialmente a partir do século XIX, quando se transformou em um recurso amiúde explorado e consagrado por uma gama imensa de autores, como Hoffmann, Edgar Allan Poe, Dostoievski, Oscar Wilde, Heinrich Heine, Machado de Assis..., mostrando-se um terreno fértil para se refletir acerca de zonas limítrofes que demarcam a interseção e a reversibilidade entre fenômenos complementares como identidade e alteridade, normalidade e loucura, realidade e ficção, entre outros.

O conto de Borges haure dessa longa tradição do tema do duplo, apropria-se de seus elementos, a começar, evidentemente, pelo espelho, mas sua originalidade é transportar o duplo da esfera do estudo psicológico à da reflexão metafísica do que constitui a realidade e o poder da ficção.

Na qualidade de uma duplicação que ameaça um original, Uqbar representa as primícias de um duplo, duplo, porém, fantasmagórico, como uma sombra que começa a ganhar vida. Não um duplo de um protagonista, um personagem a ser replicado. Antes, Borges extrai do duplo a essência do ser máscara - porquanto envolva tradicionalmente a réplica de uma persona - e assinala com Uqbar uma forma obscura de duplo que duplica de maneira borrada e difusa a máscara da realidade. Sua primeira menção, no entanto, é ambígua: Uqbar é um estranho e desconhecido lugar situado de forma vaga e imprecisa num território não-localizável pretensamente desse mundo, cuja geografia é composta majoritariamente de elementos e paisagens autorreferentes, precisando as fronteiras dessa região com quase nenhum dado cartográfico que se conheça, à exceção de umas três indicações, que mais dificultam que facilitam territorializá-lo. Uqbar, portanto, é um amálgama de algo alienígena, na qualidade de absolutamente outro, desconhecido, não-familiar, e algo que parece fazer parte deste mundo, sendo-lhe vagamente próximo. Como território não territorializável no globo terrestre, ele se insinua como sinédoque do mundo: parte ou fragmento que concentra em si o todo, mas o enverga de tal forma que faz do todo estranhamente apenas uma parte de algo ignoto, apenas suspeitado, de que se tem somente uma impressão vaga. 
É nesse nó geográfico que através do artigo de uma edição específica de uma enciclopédia que é reimpressão de uma outra que vem ao conhecimento que a literatura de Uqbar é toda de caráter fantástico, não se referindo jamais “jamais à realidade, mas às duas regiões imaginárias de Mljenas de Tlön”2. Ademais, que há uma distinção entre ortodoxos e heresiarcas, tendo aqueles se refugiado nas ilhas onde se exumam espelhos de pedra, ao passo que estes eram os que abominavam espelhos e cópulas.

A escassez de informações que eram vagas e imprecisas sobre Tlön, na primeira parte do conto, cede lugar à abundância e a precisão na segunda parte. Parte que se enceta com uma nova referência ao espelho. Nada fortuito: o gesto de abrir uma nova performance narrativa com tal remissão assinalaria, no fundo, uma outra projeção de imagem, na qual está refletida a imagem que se projetou na primeira, mas com teor diferencial. O teor diferencial é inerente ao movimento de duplicação que um espelho efetua, ao que se acresce ainda como que a projeção de imagem substancia gestos de especulação, pensamento que prolifera realidade a partir da realidade imagética na qual o pensamento se projeta. O que confirma esta dupla função do espelho é, como saberemos mais tarde, que para os habitantes de Tlön, tanto para os que abominam espelhos como para os que os escavam, a substância da realidade é puro pensamento.

Na segunda parte do conto, chega às mãos do narrador-personagem, em circunstâncias extraordinárias dois anos depois de se deparar pela primeira vez com a menção de um suposto ou falso país chamado Uqbar, um livro escrito em inglês de lombada amarela de couro, onde consta a inscrição de título: A First Encyclopaedia of Tlön. Vol. XI. Hlaer to Jangr³. Sem menção de data ou lugar, esse volume compunha-se de 1001 páginas. No número de páginas há de forma difratada ou simplesmente opaca um espelhamento: a presença remota aqui, mas sempre constante, d'As mil e uma noites no corpus borgeano, fonte de leituras, releituras, intertextualidade, inspiração, estímulo, emulação e, sobretudo, vitalidade da narrativa de Borges. O traço velado mileumanoitesco $0^{4}$ de Tlön no número total de suas páginas é uma marca indelével na natureza de

2 BORGES, Tlön, Uqbar, Orbius Tertius, p. 115.

3 BORGES, Tlön, Uqbar, Orbius Tertius, p. 116.

4 Devo creditar a invenção desse imaginativo e poético adjetivo a Mamede Mustafa Jarouche, em seu belíssimo ensaio introdutório, intitulado Uma poética em ruínas, presente na edição de sua tradução ao primeiro volume do Livro das mil e uma noites. As referências completas seguem ao final do texto. 
Tlön quanto à incompletude da criação literária, que na série sequencial de noites estabelece o compasso de sua criação continuamente descontinuada, refazendo-se a cada noite com uma criação nova, sendo porém atravessada pelo puro gesto cosmogônico de contar, depois de renovar através dos sonhos da imaginação literária as energias gastas durante o dia. A enciclopédia de Tlön é o mundo da literatura encarnando a dupla potência latente d'As mil e uma noites: a de ser uma obra inacabável na qual se condensa a literatura como um todo na sua tarefa infinita, nesse aspecto sendo sua sinédoque; a de duplicar As mil e uma noites, sendo portanto o duplo desta obra, duplo cujo função precípua é a ameaçar e substituir aquilo que se mostra como contrapartida d'As mil e uma noites, a saber, o mundo que acontece durante as horas do dia, o mundo das atividades e labores da vida, o mundo real sobre o qual se debruça a metafísica. Neste sentido, ao difratar na forma de sinédoque a literatura, Tlön haure de um poder de duplicar diferenciadamente o mundo.

E se na primeira parte do conto apresenta-se Uqbar como localidade não-localizável do mundo para findar em Tlön como região imaginária da literatura de Uqbar, na segunda parte Tlön metamorfoseia-se, duplicando-se e diferindo-se, pois, de si mesmo, integrando-se a um mundo absolutamente outro que o terrestre, mundo que, contudo, é contraimagem da Terra, cuja identidade se expressa por seu nome, Orbius Tertius, e por seu símbolo, um óvalo azul, presente no frontispício do tomo décimo primeiro da enciclopédia 5 .

A composição desse "cosmo e as íntimas leis que o regem"6 é tão cheia de diversidade, sutilezas, variedades a ponto de conferir a imediata certeza de não se tratar de invenção de um único autor, mas de uma pluralidade de intelectuais das mais diferentes áreas, como astrônomos, biólogos, engenheiros, metafísicos, poetas, químicos, algebristas, moralistas, pintores, geômetras... Assim, também a suposta autoria da enciclopédia de Tlön deveria ser tão múltipla quanto à da enciclopédia na qual pela primeira vez o nome de Uqbar irrompeu. Nenhum indivíduo seria capaz de dominar os múltiplos saberes que compõe o mundo de Tlön, tampouco conferir-lhe um plano sistemático, e ajustá-los de acordo com ele.

5 BORGES, Tlön, Uqbar, Orbius Tertius, p. 116.

6 Idem, ibidem, p. 117. 
Na hipótese de haver um único inventor de Tlön, forçoso que fosse "um infinito Leibniz"7. Leibniz é, com efeito, evocado pelo narrador como o primeiro de uma série de metafísicos modernos cujas doutrinas possuem pontos de convergência com os metafísicos de Tlön: Hume, Berkeley, Spinoza, Schopenhauer... Esta remissão gravita ao redor das premissas do idealismo que caracterizam as nações de Orbius Tertius, determinando fundamentalmente sua linguagem e todas as obras do espírito que são criações derivadas da linguagem, como a religião, as letras e a metafísica.

O nome de Leibniz figura entre uma impossível autoria única e uma absoluta autoria múltipla, o nome de Leibniz, portanto, é uma marca dessa ausência autoral e de radical anonimato de onde Tlön se gera. A remissão do narrador a Leibniz é motivada tanto pelo princípio leibniziano de identidade dos indiscerníveis, pelo qual não pode haver duas mônadas ou substâncias indiferenciadas, pois, caso contrário, deveriam ser uma única, quanto pelo fato de ter erigido todo o programa de sua doutrina filosófica um movimento contínuo e insuperável de espelhamento e simulacros, com todas as mônadas espelhando diferenciadamente uma simulação múltipla que a mônada divina e suprema, da qual o autor ausente de Tlön é um duplo, simula como realidade viva, mas que essencialmente é puro jogo performativo de espelhamentos e de narrações entre substâncias que jamais se tocam ou se aproximam.

As palavras de Leibniz na Monadologia de que cada substância é "um perpétuo espelho vivo do universo" 8 valem para a natura naturans metafísico-ficcional de Tlön. Em consonância a essa desmaterialização das substâncias, Borges escreve: “O mundo para eles [habitantes de Tlön] não é um concurso de objetos no espaço; é uma série heterogênea de atos independentes. É sucessivo, temporal, não espacial." ${ }^{\circ}$ A desespacialização do mundo, a princípio, pode aqui identificar-se à primeira vista aos esforços filosóficos que vão de Leibniz a Kant de conferir ao espaço o status ontológico de pura fenomenalidade. Porém, é preciso recordar a abominação aos espelhos e a cópula dos heresiarcas de Tlön, e ter em fito que a essência de Tlön é a de, espelhando, duplicar, originando uma imagem similar, mas diversa, fazendo da reversão uma inversão radical de substância. Assim, privar o espaço de sua espacialidade é um gesto

7 Idem, ibidem, p. 117.

8 STRICKLAND, Leibniz's Monadology: a new translation and guide, p. 25.

9 BORGES, Tlön, Uqbar, Orbius Tertius, p. 118. 
literário de dar primazia fundamental ao tempo como puro movimento de geração heterogênea de ações e simulações, temporalidade, porém, que deve ser antes percebida essencialmente como contraimagem da narrativa ficcional. A temporalidade no mundo de Tlön é um espelhamento da tessitura ficcional que multiplica os acontecimentos da realidade como se fossem novos e singularíssimos contos que atravessam as mil e uma noites, saltando de um instante ao outro para a infinita heterogeneidade de sua natureza poético-linguística.

Dessubstancializado, o tempo é um espelho vivo da linguagem, esse poder de representação - representação que, como espelhamento vivo, é essencialmente ato de criação mediante duplicação, o que faz do suposto original nada mais que também um duplo e uma obra (retroativa ou não) de ficção. Nas línguas de Tlön, em seus dois hemisférios, não há substantivos. No hemisfério boreal, diz o narrador que "há verbos impessoais, qualificados por sufixos (ou prefixos) monossilábicos de valor adverbial”' , de forma que não há palavra, por exemplo, para lua, "mas há um verbo que seria em espanhol lunecer ou lunar. Surgiu a lua sobre o rio diz-se hlör u fang axaxaxas mlö"11, que traduzido: "atrás duradouro-fluir luneceu." ${ }^{12}$ No hemisfério austral, “a célula primordial não é o verbo, mas o adjetivo monossilábico. O substantivo forma-se por uma cumulação de adjetivos. Não se diz lua: diz-se aéreo-claro sobre escuro-redondo.”'3 A língua desse hemisfério pode nomear não apenas coisas existentes, mas tem o poder também de convocar e dissolver objetos ideais, além de criar indefinidamente por esse processo de aglutinação adjetival coisas e objetos, revertendo a privação de substantivos nucleares na capacidade interminável de multiplicá-los e dar-lhes vida.

Na duplicidade linguística de Tlön reside o mistério de sua natureza. O monismo ou idealismo que marcam a metafísica de Tlön são o duplo da força de representação que historicamente na filosofia moderna se mostrou como substância, mônada, subjetividade transcendental, egoidade, espírito, natureza, absoluto... cuja tendência principal é a de subverter a ordem do mundo, transformando-o em um espetáculo, em puro

\footnotetext{
10 Idem, ibidem, p. 118.

11 Idem, ibidem, p. 118.

12 Idem, ibidem, p. 118.

13 Idem, ibidem, p. 118.
} 
processo em que se instala o devir como consecução de uma obra de escrita invisível e intangível. Se no idealismo há aquilo que Hegel um dia designou como o mundo invertido ${ }^{14}$, em que o fenômeno é preenchido pelo conteúdo do suprassensível que lhe é homônimo, nada obstante, inoculando nele o absoluto heterônimo, proliferador das diferenças, toda a metafísica de Tlön erige-se sob a inversão de imagem dessa inversão, subvertendo o idealismo terráqueo, que buscar explicar o mundo real, com o idealismo subversivo de Orbius Tertius, que o desconstrói para reforjá-lo sob diversas e outras configurações. O paralelo que o autor-narrador-personagem faz entre uns e outros, antes de nos sugerir que sobrescrevêssemos à interpretação da metafísica tlöniana nosso tão familiar idealismo, deve figurar diante de nós como algo inquietantemente estranho, como uma miragem que lança mão de elementos reconhecíveis para indicar um outro. Esse outro é um duplo, duplo que é sempre múltiplo, metástase de mundo, metástase da literatura, da vida e, finalmente, da própria escrita.

Toda a metafísica de Tlön fundamenta-se na ação de transubstanciar a realidade, retirando o véu que sempre a encobre: revelando que sua substancialidade é puramente obra de ficção, em que toda a metafísica não passa de uma gigantesca criação literária. Mas não representa somente a desconstrução de uma metafísica realista, também da idealista. Toda metafísica é uma obra atravessada pela ficcionalidade mileumanoitesca da linguagem, que assim como o tempo, é condição absoluta de possibilidade. Disso não resulta, contudo, nenhum agravo à metafísica. Ao contrário, consiste no ajuste de contas com a sua essência. Ao duplicar nos metafísicos de Tlön a imagem dos idealistas, duplicando nisso a essência narrativa de Sherazade, Borges mostra que o único gesto que confere substancialidade às coisas, aos fenômenos, aquilo que na série heterogênea dos eventos surge e que é irredutível e irrepetível singularidade, é o ato de nomear. Ação da linguagem de coser imagens e mundos em devir, não coisas. A privação dos substantivos nas línguas de Tlön é indício não de sua pobreza de nomear e de expressar; antes, do seu poder de proliferação, de multiplicação ao infinito. Sua não-substantividade é a essência do seu processo prolífero de substanciar linguisticamente imagens e mundos. As duas línguas de Tlön encarnam seus dois hemisférios, configuram a geografia e os territórios vastos desse duplo do mundo. São duas modalidades radicalmente heteróclitas de configuração de realidade, e aquilo que parece

14 Cf. HEGEL, Fenomenologia do espírito: volume I, p. 111. 
ser um único evento real é articulado e modulado em formas diversas, como reflexos distintos de um espelho duplo. A partir disso não há mais original: o mundo invertido é também uma realidade subvertida, o duplo torna duplo o único, multiplica aquilo que outrora pretendera ser uno e o reduz a uma absoluta não-unicidade.

Nesse conto de Borges, é preciso antes de tudo penetrar nessa natureza ímpar da linguagem ficcional como processo de transubstanciação da realidade, movimento que, porém, reconfigura a metafísica desse mundo em ficcionalidade que o instaura. Os elementos procedurais dessa duplicação, como a sinédoque, a metástase, as transubstanciações moduladas pela linguagem, a apocrificidade de sua origem, o anonimato monadológico da autoria, mostram-se como um conjunto de recursos sobre os quais se delineia uma imagem. No final do Post-scriptum, Tlön ameaça diluir todas as línguas, englobar e dominar o mundo inteiro. Tudo converte-se gradativamente em Tlön, este nome que evoca a princípio uma literatura fantástica de um povo fantasma, depois um planeta chamado Orbius Tertius, e finalmente a obra magna de uma sociedade secreta... Em todas essas metástases espelham-se ficção e realidade, ambas como um duplo de um poder absoluto, e que Freud diagnosticará, tratando do estranho (das Unheimliche) presente na literatura em que aparece o duplo, da "onipotência do pensamento"15. Contudo, como Tlön revela, esse pensamento não é de sujeito algum, não se atrela a nenhum inconsciente ou consciente, apesar de ser, de qualquer forma, um poder reprimido, cuja repressão é constantemente efetuada pela metafísica da realidade. É a onipotência de uma força essencialmente anônima - diante da qual o narrador-autor-personagem (esse múltiplo e híbrido duplo) deve resignar-se por fim a ser meramente um tradutor. É a onipotência plástica da escrita, a ficção literária que materializa realidades, de que é símile e sinédoque As mil e uma noites, a qual, por seu turno, é transubstanciada nas múltiplas metástases deste duplo: Tlön, Uqbar, Orbius Tertius.

15 FREUD, O estranho, p. 61. 


\section{REFERÊNCIAS BIBLIOGRÁFICAS}

BORGES, Jorge Luis. Tlön, Uqbar, Orbius Tertius. In: OCAMPO, Silvina (org.). Antologia da literatura fantástica. São Paulo: Cosac Naify, 2013, p. 113-124.

DOSTOIEVSKI, Fiodor. O duplo. São Paulo: Ed. 34, 2011.

FREUD, Sigmund. O estranho. In: PEREIRA, Iuri (org.). Escritos sobre literatura. São Paulo: Ed. Hedra, 2014.

JAROUCHE, Mamede Mustafa. Uma poética em ruínas. In: ANÔNIMO. Livro das mil e uma noites, volume I: ramo sírio. Trad. Mamede Mustafa Jarouche. São Paulo: Globo, 2006.

HEGEL, Georg Wilhelm Friedrich. Fenomenologia do espírito: volume I. Petrópolis: Vozes, 1992.

STRICKLAND, Lloyd. Leibniz's Monadology: a new translation and guide. Edinburgh: Edinburgh University Press, 2014. 